\title{
How do the educational attainment and labour market outcomes of foreign-born adults compare to their native-born peers?
}

EDUCATION INDICATORS IN FOCUS DECEMBER 2018 \#65

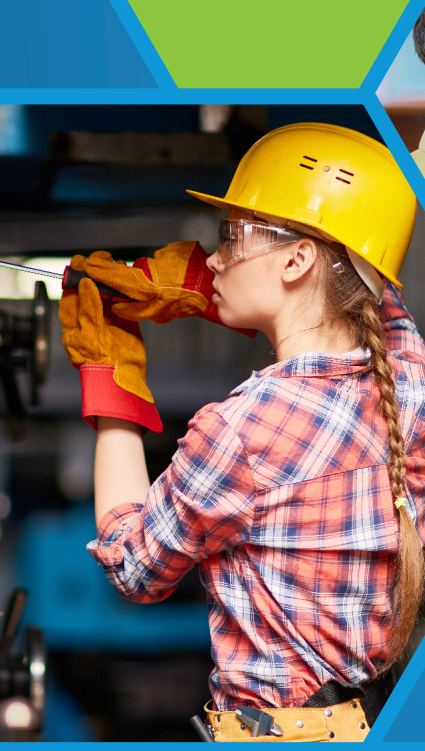




\section{How do the educational attainment and labour market outcomes of foreign-born adults compare to their native-born peers?}

- In about half of OECD and partner countries, foreign-born adults are more likely to have a tertiary education than their native-born peers. This is particularly true in countries such as Australia, Canada and New Zealand whose selective migration policies are designed to attract highly educated and skilled migrants.

- In most countries, tertiary-educated foreign-born adults have lower earnings than tertiary-educated native-born ones, and their employment rates are consistently lower.

- Foreign-born young adults (15-29 year-olds) who arrived in the host country aged 16 or older are less likely to be in the education system or the labour market than those who arrived when they were younger.

The qualification levels of foreign-born adults vary greatly across countries. Around the world, about 258 million people were living outside their country of birth in 2017, and about half of all these migrants were living in OECD countries. While migration is not a new phenomenon, the data suggest that that migration is unlikely to slow down in the coming years (OECD, 2017 ${ }_{[1]}$ ).

On average of OECD countries, 17\% of the total population aged 25-64 are foreign born, but the size and the characteristics of the foreign-born population vary both across and within countries, partly because of historical background and migration policies. In Australia, Luxembourg, New Zealand and Switzerland at least one-third of adults were born outside the country they live in. In contrast, in Chile, the Czech Republic, Hungary, Mexico, Poland and the Slovak Republic less than 5\% of adults are foreign born (OECD, 2018 ${ }_{[2]}$ ).

Contrary to popular belief, migrants are not a homogenous group of low-educated people; rather, they are a diverse group with varying educational attainment. In many countries, foreign-born adults have higher educational attainment levels than their native peers.

In about half of OECD and partner countries with available data, tertiary education rates are higher among foreign-born adults than among native-born adults. For instance, in Australia 57\% of foreign-born adults (aged 25-64) have a tertiary degree, compared to $36 \%$ of native-born adults, a difference of about 20 percentage points. In Canada, Ireland, Israel, Luxembourg, New Zealand and Portugal the share of tertiary-educated foreign-born adults also exceeds that of native-born adults by 10 percentage points (Figure 1 ).

In Australia, Canada and New Zealand the reasons for this outcome include selective migration policies designed to attract highly educated and skilled migrants. In other countries, such as Ireland or Luxembourg, specialised labour markets in the financial and government sector attract a large number of highly educated people. Moreover, these English-speaking countries take advantages of their international language which contribute to attract more qualified migrants.

In many OECD countries, a smaller share of foreign-born adults than native-born adults is lacking upper secondary education. For instance, in Australia only 14\% of foreign-born adults have not gained an upper secondary education while among native-born adults the share is $22 \%$ (OECD, 2018 $\left.{ }_{[2]}\right)$.

While in many countries foreign-born adults are more likely to be highly educated people, in other countries the educational attainment of foreign-born adults is much lower than that of their nativeborn peers. 


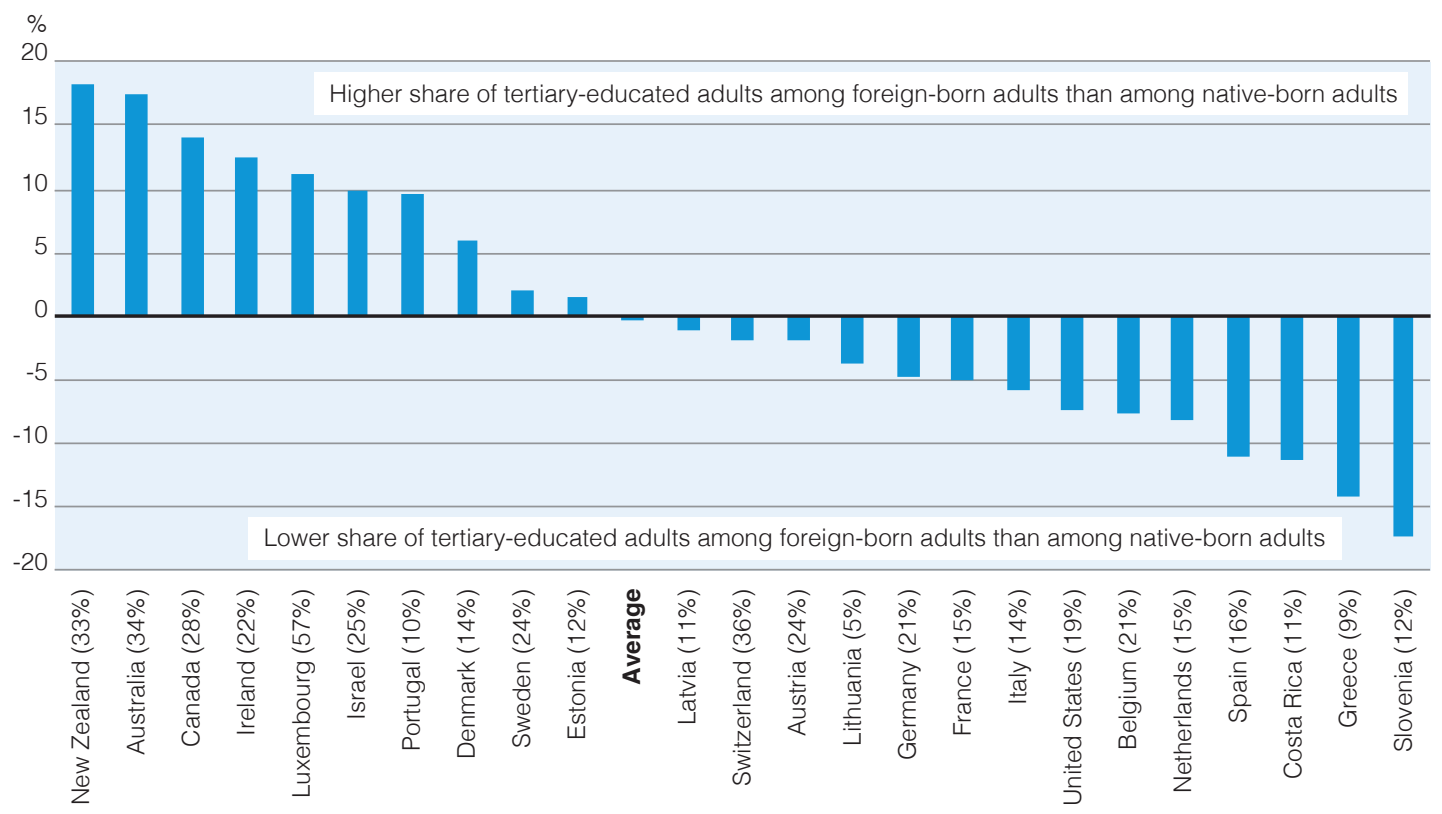

Note: The percentage in parentheses represents the share of foreign-born adults among 25-64 year-olds. Countries with a share of less than $5 \%$ of foreign-born adults have been excluded.

Source: OECD, 2018 ${ }_{[2]}$, Table A1.3. See Source section for more information and Annex 3 for notes (http://dx.doi.org/10.1787/eag-2018-36-en).

In Slovenia, the tertiary education rate for foreign-born adults is about half of that of native-born adults (19\% compared with 37\%), a difference of just under 20 percentage points. In Costa Rica, Greece and Spain, tertiary-attainment rates are more than 10 percentage points lower among foreign-born adults (Figure 1).

Similarly, all the countries with smaller shares of tertiary-educated foreign-born adults also have a smaller share of foreign-born adults who have attained upper secondary education than among native-born adults. In Germany, 32\% of foreign-born adults do not have upper secondary education, more than three times the rate among native-born adults (9\%). In Austria, Belgium, Costa Rica, Greece, Italy, France, Switzerland and the United States, the difference is still more than 10 percentage points (OECD, 2018 ${ }_{[2]}$ ).

\section{Foreign-born adults generally have lower employment rates and lower earnings than their native-born peers, but there are some exceptions}

Across OECD countries, labour market outcomes for the foreign-born population tend to lag behind those of the native born. Foreign-born adults are more likely to be unemployed or inactive and, when they are employed, more likely to earn less than their native-born peers with similar educational attainment.

The likelihood of being employed increases with educational attainment, but more steeply for nativeborn than foreign-born adults. On average across OECD countries, there is a 29 percentage-point difference in the employment rate between native-born adults with below upper secondary education $(57 \%)$ and those with tertiary education (86\%). This difference is 18 percentage points for foreign-born adults (60\% and $78 \%$, respectively). In other words the employment advantage of greater educational attainment is smaller for foreign-born than for native-born adults (OECD, 2018 ${ }_{[2]}$ ).

Among all the OECD and partner countries where at least 5\% of adults are foreign born, tertiaryeducated foreign-born adults have worse employment prospects than their native-born peers. Relative employment rates show that tertiary-educated foreign-born adults in Austria, Belgium, Estonia, France, Germany, Italy, Latvia, Spain, Sweden and Switzerland are more than 10\% less likely to be employed than equally educated native-born adults (Figure 2). 


\section{FIGURE 2 / Employment rate and earnings of foreign-born adults relative to native-born adults (2017)}

Tertiary-educated 25-64 year-olds; native-born adults = 100

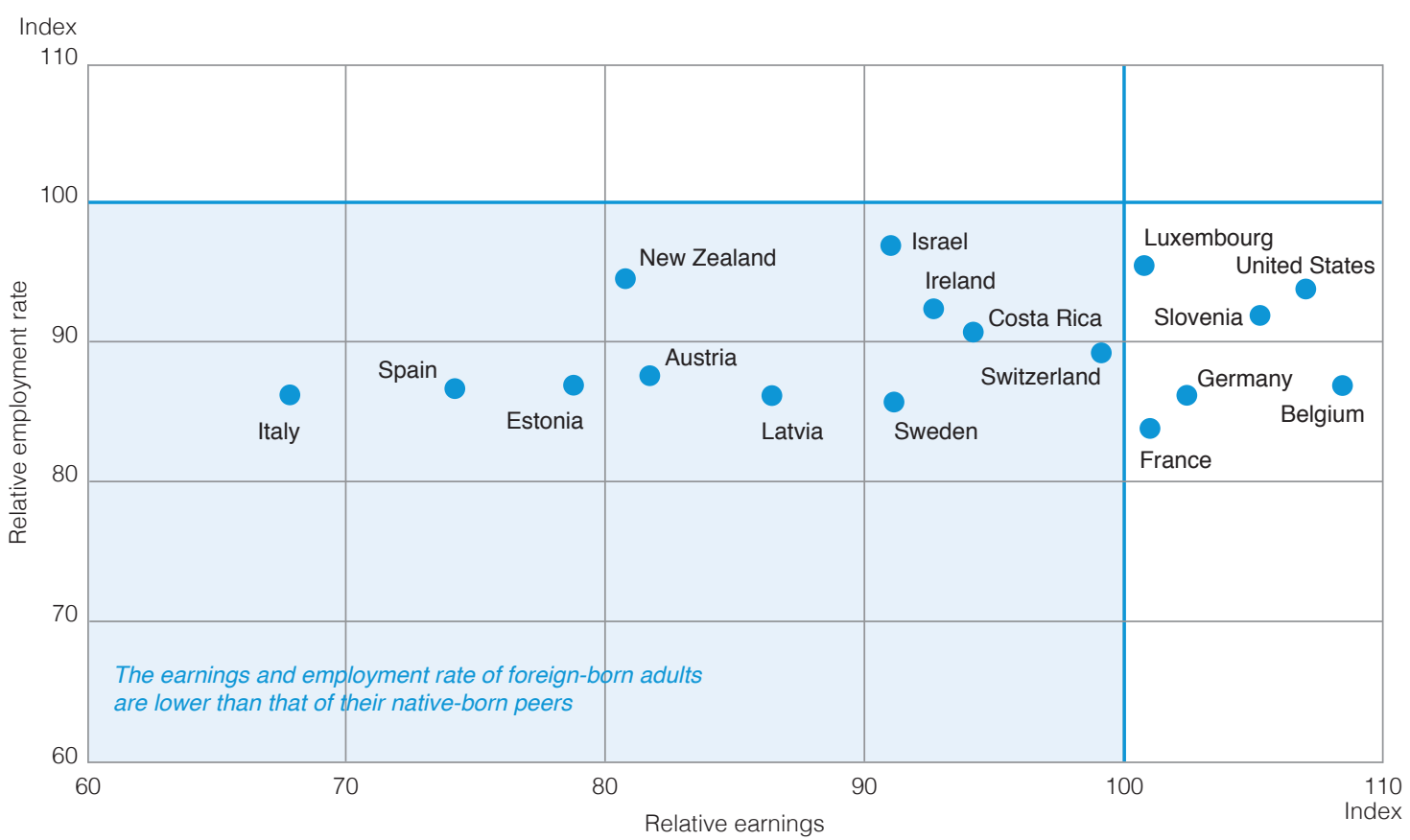

Note: Earnings refer to income from employment for full-time workers. Countries with a share of less than $5 \%$ of foreign-born adults have been excluded.

Source: OECD, 2018 ${ }_{[2]}$, Table A1.3. See Source section for more information and Annex 3 for notes (http://dx.doi.org/10.1787/eag-2018-36-en).

In Belgium, Slovenia and the United States, foreign-born adults with tertiary education who manage to find a job earn at least 5\% more than their native-born peers. However, in most countries, tertiary-educated foreign-born workers earn less than similarly educated native-born adults. The biggest earnings gap is found in Italy, where foreign-born adults with tertiary education are paid only $68 \%$ of the earnings of their native-born peers. In Austria, Estonia, Latvia, New Zealand and Spain, the earnings of foreign-born adults are more than 10\% lower than those of native-born adults (Figure 2).

Among lower educated workers, there is also a significant earnings disadvantage for foreign-born adults compared to their native-born peers. However, there are two exceptions: in Germany and Switzerland foreign-born workers without upper secondary education earn more than their nativeborn peers (18\% and 6\% respectively) (OECD, 2018 $\left.{ }_{[2]}\right)$.

Moreover, while foreign-born adults with tertiary education have lower employment prospects than their native-born peers, the employment prospects of foreign-born adults without upper secondary education are mixed. In Greece, Israel, Italy, Luxembourg, Slovenia and the United States foreignborn adults without upper secondary education are over 10\% more likely to be employed than equally educated native-born adults (OECD, 2018 ${ }_{[2]}$ ).

This wide variety of labour market outcomes of foreign-born adults relative to their native-born peers shows that the national context and policies, and the characteristics of the foreign-born population have an effect on their employment prospects.

Many factors other than educational attainment can affect the employment rates and earnings of the foreign-born population. For example, the difficulty of getting recognition for foreign qualifications can have detrimental effects on the hiring process, including the negotiation of starting wages. Language - and discrimination - can also be barriers that add to the difficulties of the job search and may lead to a foreign-born adult taking a lower position than might be expected given their qualifications. Foreign-born adults may also be less able to draw on social and professional networks in the host countries. They may therefore be inclined to accept any job they can find on their arrival, even if it does not match their qualifications (OECD, 2018 [3]; OECD, 2018 $\left.{ }_{[4]}\right)$. 


\section{Migrants who arrived at a younger age are generally more likely to be employed or in education}

In most countries, the employment rates for foreign-born adults who arrived by the age of 15 are higher than for those who arrived in the country when they were older. For instance, in Greece, Italy and Portugal, 25-64 year-olds who arrived by the age of 15 have an employment rate around 20 percentage points higher than those who arrived after the age of 15 (OECD, 2018 ${ }_{[2]}$ ).

On average across OECD and partner countries where at least 5\% of 15-29 year-olds are foreign-born, one-quarter of foreign-born 15-29 year-olds who arrived in the country after the age of 15 are neither employed nor in education or training (NEET) compared with only 15\% of those who arrived by this age. In Greece, Italy and Spain, more than $40 \%$ of young adults who arrived in the country after the aged of 15 are NEET, more than 15 percentage points higher than the respective shares of those who arrived when they were younger. In Germany, the difference between these two groups is almost 3 times as large: 32\% of foreign-born young adults who arrived later in life are NEET, compared with less than $11 \%$ of foreign-born adults who arrived by the age of 15 (Figure 3).

One explanation for this difference is that foreign-born adults who arrived in a country at a young age have spent some years in its education system, and so acquired the necessary proficiency in the language of the host country and also gained qualifications recognised by their host country (OECD, $\left.2018_{[3]}\right)$. Therefore, it will be important for countries to provide foreign-born adults with the necessary education and training, or recognised qualifications to increase their employment prospects.

However, some countries including France, Ireland and New Zealand not only have some of the lowest NEET rates for foreign-born young adults, but their age of arrival makes almost no difference in these countries. The rates are also comparable to those for their native-born peers.

Countries who manage to create education opportunities for both native- and foreign-born young adults reduce the inequalities between them by ensuring they develop the skills needed for their labour markets. These countries are also giving foreign-born young adults more chances to stay in the education system and the labour market.

When needed, countries could make greater efforts to evaluate and recognise foreign qualifications that would improve the integration of foreign-born adults into their new communities and into the labour market (OECD, $\left.2017_{[1]}\right)$.

FIGURE 3 / Percentage of native- and foreign-born 15-29 year-old NEETs, by age at arrival in the country (2017)

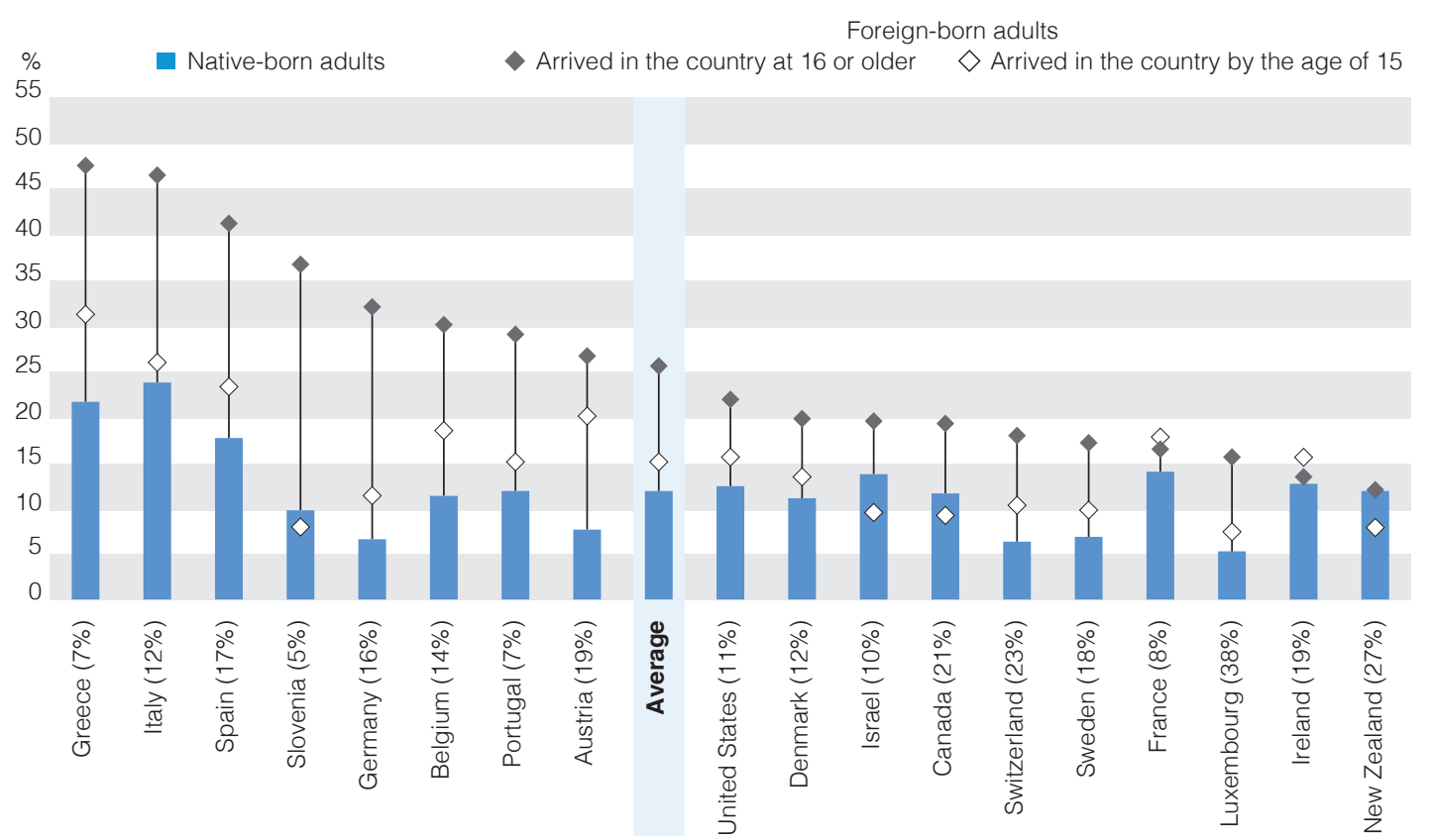

Note: NEET refers to young people neither employed nor in education or training. The percentage in parentheses represents the share of foreign-born 15-29 year-olds. Countries where less than 5\% of the population aged 15-29 are foreign born are not shown.

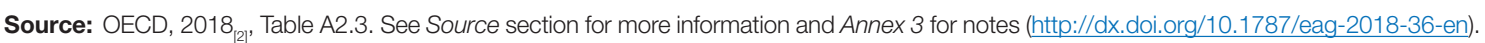




\section{The bottom line}

Adult migrants in all OECD countries are a diverse group, with different profiles and levels of education. Even if they hold tertiary degrees, they are more likely to have poorer labour market outcomes, including lower earnings. Participation in the labour market is more difficult for foreignborn adults who arrived at a later age and acquired their qualifications in another country. It is important that host countries design and implement policies that will help immigrants improve their chances in their labour market, benefitting both the person and the country.

\section{FOR MORE INFORMATION:}

[1] OECD (2017), International Migration Outlook 2017, OECD Publishing, Paris, http://dx.doi.org/10.1787/migr_outlook-2017-en.

[2] OECD (2018), Education at a Glance 2018: OECD Indicators, OECD Publishing, Paris, http://dx.doi.org/10.1787/eag-2018-en.

[3] OECD (2018), Skills on the Move: Migrants in the Survey of Adult Skills. In OECD Skills Studies. OECD Publishing, Paris, https://dx.doi.org/10.1787/9789264307353-en.

[4] OECD/EU (2018), Settling In 2018: Indicators of Immigrant Integration, OECD Publishing, Paris/EU, Brussels, https://dx.doi.org/10.1787/9789264307216-en.

$\begin{array}{ll}\text { VISIT } & \text { www.oecd.org/education/education-at-a-glance-19991487.htm } \\ \text { Education Indicators in Focus (previous issues) } \\ \text { PISA in Focus } \\ \text { Teaching in Focus }\end{array}$

NEXT TOPIC Where do inequities in education start appearing?

\section{a) $O E C D$}

\section{CONTACT:}

Markus Schwabe (Markus.Schwabe@OECD.org)

Vanessa Denis (Vanessa.Denis@OECD.org)

Simon Normandeau (Simon.Normandeau@OECD.org)

Photo credit: @ Christopher Futcher / iStock; @ Marc Romanelli / Gettyimages; @ michaeljung / Shutterstock; @ Pressmaster / Shutterstock This work is published under the responsibility of the Secretary-General of the OECD. The opinions expressed and arguments employed herein do not necessarily reflect the official views of OECD member countries.

This document, as well as any data and any map included herein, are without prejudice to the status of or sovereignty over any territory, to the delimitation of international frontiers and boundaries and to the name of any territory, city or area.

The statistical data for Israel are supplied by and are under the responsibility of the relevant Israeli authorities. The use of such data by the OECD is without prejudice to the status of the Golan Heights, East Jerusalem and Israeli settlements in the West Bank under the terms of international law. 